\title{
Reprocessamento de artigos críticos em unidades básicas de saúde: perfil do operador e ações envolvidas
}

\author{
Reprocessing critical devices in a primary health care unit: worker's profile and developed actions
}

Reprocesamento de artículos criticos en unidades básicas de salud: perfil del operador y acciones desarrolladas

\section{Lidiana Flora Vidôto da Costa', Maria Isabel Pedreira de Freitas"}

'Universidade Paulista. Curso de Graduação em Enfermagem. Campinas, SP

"Universidade Estadual de Campinas. Faculdade de Ciências Médicas, Departamento de Enfermagem. Campinas, SP

Submissão: $12 / 12 / 2008$

Aprovação: 29/09/2009

\section{RESUMO}

Estudo descritivo-exploratório Que teve como objetivo conhecer o perfil e ações do operador do reprocessamento de artigos críticos nas unidades básicas de saúde de um município do Estado de São Paulo. Das 34 unidades básicas de saúde, verificou-se Que 32,4\% destes operadores receberam treinamentos admissionais e $8,8 \%$ há menos de um ano. Eles exerciam funções concomitantes ao reprocessamento como: imunização ( $11,7 \%)$, curativos $(26,4 \%)$ e coletas de exames $(23,5 \%)$. Esses resultados podem influenciar negativamente na Qualidade do processo, limitando o controle de infecção nos locais estudados.

Descritores: Recursos humanos de enfermagem; Esterilização; Serviços de saúde;

\section{ABSTRACT}

Descriptve-exploratory study that aimed to outline the profile and the actions of workers who conduct the reprocessing of critical devices at primary health care units in a city in the State of São Paulo. Thirty-four primary health care units were surveyed. Individuals responsible for reprocessing are nursing assistants (88.2\%), that conducted concomitantly activities related to immunization (11.7\%), dressing (26.4\%) collection of samples for exams (23.5\%); $32.4 \%$ had received training at the beginning of their reprocessing activities, and $8,82 \%$ at least one year before. The lack of dully skilled individuals may influence the Quality of the process and constitute a limiting factor for the control of cross infection.

Descriptors: Nursing staff, Sterilization; Health services;

\section{RESUMEN}

Estudio descritivo-exploratório Que tuvo como objetivo conocer el perfíl y las acciones del profesional Que realiza reprocesamiento de artículos críticos en las unidades básicas de salud en un municipio del Estado de São Paulo. Fueron estudiados 34 ubidades, en donde los responsables por el reprocesamiento son los auxiliares de enfermería $(88,2 \%)$. Ejercian simultaneamente: actividades con inmunización $(11,7 \%)$, curativos $(26,4 \%)$ y colectas de examenes $(23,5 \%) ; 32,4 \%$ recibieron entrenamientos en la admission y $8,82 \%$ hace menos de un año. Estos resultados pueden influenciar en la calidad del proceso y ser um factor limitante para el control de infección cruzada en los locales estudiados.

Descriptores: Personal de enfermería; Esterilización; Servicios de salud. 


\section{INTRODUÇÃO}

Com as mudanças decorrentes do processo de institucionalização do Sistema Único de Saúde, os cuidados primários à saúde vem desenvolvendo práticas assistenciais mais eficientes e efetivas, aumentando a demanda de pequenos procedimentos invasivos realizados nas Unidades Básicas de Saúde $(\mathrm{UBS})^{(1)}$. Artigos críticos utilizados nesses procedimentos são reprocessados nas próprias UBS. A complexidade eue envolve o reprocessamento de artigos críticos, e suas implicações, exigem Que o responsável o faça com habilidades e conhecimento tecno-científico, dentro de métodos e critérios pré- estabelecidos. Para isso o profissional necessita deter conhecimento, seguir diretrizes e metodicamente cumprir as etapas exigidas. Precisa ter conhecimento específico e instrumentos de trabalho Que lhe permitam desempenhar suas atribuições com competência e responsabilidade ${ }^{(2)}$.

Entende-se reprocessamento de artigo crítico como o processo de limpeza e esterilização a ser aplicado em produtos para a saúde, Que garanta a segurança na sua utilização, incluindo o controle de Qualidade em todas as suas etapas ${ }^{(1)}$. Este controle pode ser conseguido através da monitorização de cada etapa do reprocessamento, seguindo diretrizes norteadoras e legais Que facilitarão meios para se detectar as possíveis falhas no processo e se determinar as correções necessárias. Quando se trata de reprocessamento de artigos, não é admissível ter um produto final "parcialmente esterilizado". Se o reprocessamento for realizado sob condições adversas, colocarão em risco os usuários submetidos aos procedimentos Que envolvem o uso de artigos críticos, comprometendo a Qualidade e a segurança do processo.

Em contrapartida, atualmente, observa-se relevante atenção voltada à gestão em Qualidade Que lentamente passa a ser adotada pelas instituições de saúde. A preocupação com a Qualidade está deixando de ser rapidamente um diferencial e uma opção para se tornar uma necessidade, um pré-requisito básico para a sobrevivência e a competitividade das organizações do mundo moderno ${ }^{(3)}$. Seus princípios básicos, o atendimento à clientela com o fornecimento de bens e de serviços Que promovam a sua máxima satisfação e o mínimo, senão as ausências totais de riscos e falhas ${ }^{(4)}$. Portanto, falar em processo de esterilização é pensar em Qualidade de serviço favorecendo as melhores implicações ao usuário.

O reprocessamento de artigos críticos necessita seguir um planejamento para Que todo esse processo esteja sistematizado. Se processo é definido como um conjunto de causas Que gera um determinado efeito, ou como um conjunto de meios para se chegar a um determinado fim $^{(3)}$, pode-se afirmar Que para se realizar o reprocessamento de artigos críticos, deve-se conhecer cada etapa e suas implicações. Faz-se necessário uma proximidade, uma relação de conseqüência entre a ciência e a técnica, o pensar e o agir ${ }^{(5)}$. Portanto, o reprocessamento deve ser realizado como consęuência originária das bases de conhecimentos, critérios e recomendações legais e de órgãos representativos. Assim sendo, para realizar o reprocessamento de artigos críticos é necessário domínio e conhecimento de Quem o realiza ${ }^{(6)}$.

Trabalhar com Qualidade para se realizar o reprocessamento exige um perfil profissional adequado Que atenda às exigências necessárias para a obtenção de resultados satisfatórios da Qualidade implicada. Duas organizações americanas, a American National
Standard e a Association for the Advancement of Medical Instrumentation ${ }^{(7)}$, recomendam critérios mínimos para a Qualificação do profissional como treinamento e educação, competência documentada e conhecimentos específicos sobre o tipo de esterilização adotado no estabelecimento de saúde, princípios básicos de esterilização e de transmissão de doenças infecciosas e controle de infecção. Devem dominar o conhecimento das etapas do reprocessamento e serem capazes de realizar a limpeza, inspeção e empacotamento, procedimentos de esterilização, operação de equipamento, armazenamento e precauções de segurança, apresentando experiência mínima e comprovada de dois anos. É importante a existência de profissionais Qualificados, para não expor a população usuária aos riscos de infecção.

O conhecimento em saúde é um processo dinâmico e flexível tornando-se imprescindível Que, o profissional esteja sempre buscando o aprendizado, atualizando-se de forma contínua, para não se perder no contexto histórico e na evolução das práticas ${ }^{\left({ }^{8}\right)}$.

No Brasil, a força de trabalho dos serviços de saúde é composta, em sua grande maioria, por trabalhadores de enfermagem de nível médio (técnicos e auxiliares), e Que executam as ações de enfermagem. Esses profissionais contribuem para estabelecer o padrão de Qualidade dos serviços de saúde e especialmente da enfermagem ${ }^{(9)}$.

Assim sendo, o perfil profissional do agente responsável pelo reprocessamento de artigos críticos poderá interferir, positivamente ou não, nos resultados esperados influenciando diretamente a Qualidade desse processo com reflexos na segurança do usuário do sistema de saúde.

Sabe-se que o reprocessamento é amplamente realizado em instituições hospitalares, nos Quais a Central de Material Esterilizado (CME) atende à demanda cirúrgica e dos procedimentos realizados em outros setores de assistência ao cliente. Porém, pouco se tem falado sobre o reprocessamento de artigos críticos realizados nas UBS. Procedimentos complexos Que envolvem a utilização de artigos críticos são realizados nessas unidades, e os mesmos critérios para a realização do processo no CME hospitalares devem ser seguidos.

Considerando o exposto o presente estudo pretende conhecer o perfil do operador responsável pelo reprocessamento, a capacitação profissional oferecida ao operacional, e atividades desenvolvidas pelo mesmo nas UBS em um município no interior do estado de São Paulo sendo os principais Questionamentos levantados neste estudo.

Assim sendo, este estudo teve como objetivo o perfil e ações do operador do reprocessamento de artigos críticos nas unidades básicas de saúde de um município do Estado de São Paulo.

\section{MÉTODO}

Este estudo foi realizado nas UBS de um município do interior do Estado de São Paulo. O município encontra-se dividido em cinco distritos de saúde. A divisão territorial dos distritos caracteriza-se pela densidade populacional, com áreas de abrangência maiores ou menores. Dos cinco distritos, cada um abrange distintamente, além de outros serviços de saúde, 46 unidades básicas de saúde ${ }^{(10)}$.

Tratou-se de um estudo descritivo e exploratório, cuja população é constituída pelos operadores responsáveis pelo reprocessamento de artigos críticos nas unidades básicas de saúde visitadas, no dia 
em Que se realizou a entrevista. Compreendeu inicialmente todas as 46 UBS.

Foram incluídas no estudo as UBS Que tiveram o reprocessamento de artigos críticos sendo realizado por ocupacionais no próprio local, envolvendo todas as etapas do processo de esterilização: limpeza, acondicionamento, esterilização (física ou Química), armazenamento e distribuição.

As UBS excluídas foram as Que participaram do estudo piloto, as não autorizadas como campo de investigação da pesQuisa e as Que não realizavam o reprocessamento de artigos críticos no local.

Utilizou-se um instrumento para coleta de dados previamente elaborado, construído com embasamento de diretrizes internacionais para a operacionalização e segurança para realização de processos de esterilização de artigos em serviços de saúde, da Association for the Advancement of Medical Instrumentation e American National Standard Institute: Steam sterilization and sterility assurance in health care facilities ${ }^{(7)}$ e no Guideline for Disinfection and Sterilization in Helthcare Facilities ${ }^{(1)}$ e das legislações nacionais vigentes, como a RDC $n^{\circ} 50$ de fevereiro de $2002^{(12)}$ e a RDC 307 de novembro de $2002^{(13)}$.

O instrumento é constituído de cinco partes à saber: a) caracterização da unidade básica de saúde; b) caracterização do perfil do profissional responsável pelo reprocessamento; c) caracterização dos procedimentos com artigos críticos; d) caracterização do processo de esterilização; e) verificação da área física destinada ao reprocessamento.

Devido ao complexo e rico conteúdo de dados resultantes do instrumento, possibilitou que o estudo fosse dividido em três partes. Foi previamente aplicado aos três responsáveis pelo reprocessamento de artigos críticos, em três unidades básicas de saúde, em uma versão inicial, avaliado para a identificação de falhas Que pudessem interferir na objetividade dos dados e nas interpretações dos resultados. Após a avaliação, houve necessidade de ajustes em relação à algumas frases, para melhor entendimento e compreensão do entrevistado, sendo corrigido, antes de sua utilização.

Foi aplicado na forma de entrevista e com itens para observação, contendo perguntas estruturadas e semi-estruturadas, com Questões abertas e fechadas.

O presente estudo utilizou o conteúdo das partes a e b do instrumento, com o objetivo de obter dados de identificação da unidade básica de saúde, do operador do reprocessamento, seu perfil de capacitação, o tempo de sua atuação no reprocessamento de artigos críticos, as funções designadas ao mesmo no dia da entrevista, o escalonamento de um responsável pelo reprocessamento na escala diária de trabalho da unidade básica de saúde, os procedimentos realizados na unidade básica de saúde envolvendo artigos críticos reprocessados.

A coleta de dados foi realizada no período de março a dezembro de 2006 após aprovação do projeto pelo Comitê de Ética em Pesquisa da Faculdade de Ciências Médicas da Universidade Estadual de Campinas, com Parecer no 185/2005/CAAE 0 105.0.146.00005 .

Para o início da coleta de dados, houve previamente contato telefônico com o coordenador de cada UBS, a fim de obter autorização informal para a pesquisa e agendamento de data e hora. No dia da entrevista, a autorização formal era obtida por um instrumento assinado pelo coordenador da unidade básica de saúde. Após a formalização, o pesQuisador se dirigiu ao local de ocorrência do reprocessamento, para iniciar a entrevista com o operador responsável pelo processo na unidade, mediante os esclarecimentos necessários e a anuência ao Termo de Consentimento Livre e Esclarecido.

Foi realizada, inicialmente, uma análise descritiva das variáveis e posteriormente a verificação da existência de alguma associação entre elas utilizando os testes estatísticos Qui-Quadrado de Pearson e Teste Exato de Fisher, sendo considerada significativa a associação Quando o p-valor $\leq$ a 0,05. O software utilizado foi o Minitab $15^{\circledR}$.

\section{RESULTADOS}

Das 46 unidades básicas de saúde pertencentes ao município, distribuídas nos cinco Distritos de Saúde doze foram excluídas, sendo três por participarem do teste piloto, três por não autorizarem a realização da entrevista, e seis por não possuírem o equipamento para esterilização disponível. Sendo assim, fizeram parte do estudo, 34 unidades das Quais foram entrevistados 34 operadores responsáveis pelo reprocessamento de artigos críticos no dia da entrevista.

Portanto, das 46 unidades existentes, 34 realizavam o reprocessamento de artigos críticos in loco e nove utilizam os artigos reprocessados em outras unidades, por falta de recursos tecnológicos. As demais participaram no projeto piloto.

A coordenação das unidades visitadas estava a cargo de enfermeiros (58,0\%), de odontólogos (20,6\%), de médicos (14,7\%) e de terapeutas ocupacionais $(5,8 \%)$.

Todas as unidades investigadas realizavam inúmeros procedimentos Que envolvem o uso de artigos críticos reprocessados nas atividades diárias. Desses procedimentos, todas realizavam curativos e procedimentos odontológicos, 97,0\% faziam procedimentos ginecológicos, 94,0\% realizavam suturas, 76,0\% faziam pequenos procedimentos cirúrgicos e $59,0 \%$ drenagens de abscessos

A categoria profissional dos responsáveis pela realização do reprocessamento nas unidades era Quase na sua totalidade, composta por membros da equipe enfermagem $(97,0 \%)$. Destes operadores, a maioria é composta por auxiliares de enfermagem $(88,2 \%)$, seguidos pelos técnicos de enfermagem $(8,8 \%)$, os Quais atuam em apenas três unidades e um ocupacional da área odontológica (2,9\%). Enfermeiros não realizam esta atividade em nenhuma.

A realização de práticas de esterilização dentro de critérios estabelecidos é essencial para assegurar Que procedimentos envolvendo artigos críticos não sejam responsáveis pela transmissão de infecções por patógenos aos pacientes. Observou-se Que em 91 , 1\% o reprocessamento era realizado em todas as etapas: limpeza, acondicionamento, esterilização e armazenamento dos artigos.

Em três unidades o processo era realizado de forma diferente: na primeira, um operador era responsável fixo pela limpeza dos artigos e as outras etapas eram feitas por outros colaboradores, Quando estivessem desocupados. Os artigos depois de acondicionados eram depositados na câmara esterilizadora até atingirem a capacidade máxima, Quando então era colocada em funcionamento; na segunda unidade, havia um funcionário escalado para a realização da esterilização e armazenamento, ficando as atividades de limpeza e acondicionamento a critério das pessoas que utilizaram os artigos durante limpeza e acondicionamento a critério das pessoas Que utilizaram os artigos durante atendimento aos usuários; na terceira, 
o reprocessamento de artigos críticos envolvia dois operadores distintos: um era responsável pela limpeza dos artigos e o outro pelo acondicionamento, esterilização, e armazenamento. Essa unidade também é encarregada pelo reprocessamento de artigos encaminhados por um serviço de pronto atendimento.

Para se conhecer a previsão da escala de uma pessoa exclusiva para as realizações das atividades diárias, verificou-se Que dentre as 34 unidades, $24(70,6 \%)$ faziam essa previsão. Nas unidades em Que não havia essa previsão $(29,4 \%)$ a falta de recursos humanos era a justificativa apresentada.

Para investigar se o operador responsável pelo reprocessamento estaria também realizando outras atividades, como assistência direta ao paciente, verificaram-se as funções desempenhadas por ele, no dia da entrevista.

O estudo detectou Que embora atuando como responsáveis pelo reprocessamento dos artigos, concomitantemente esses operadores atuavam auxiliando outros profissionais nas áreas de odontologia, médica e farmácia $(35,3 \%)$; realizando curativos $(26,4 \%)$; coletando exames laboratoriais e colpocitológicos $(23,5 \%)$; recepcionando clientes (26,4\%); acolhendo e orientando os clientes (1 I,7\%) e trabalhando no setor de imunização $(11,7 \%)$.

Dos ocupacionais entrevistados Que exerciam funções como limpeza de artigos, observou-se Que estes realizavam concomitantemente imunização $(8,8 \%)$ e curativos em clientes $(26,4 \%)$. Dos responsáveis pelo preparo e esterilização dos artigos, 26,4\% realizavam curativos em clientes e $73,5 \%$ coleta de exames laboratoriais (sangue, urina, fezes) e colpocitológicos.

Foi realizada a associação entre os dados obtidos por meio do Teste Exatos de Fischer, com o intuito de se identificar a significância da ocorrência de atividades concomitantes, Que de alguma forma pudessem trazer riscos operacionais ao usuário e/ou ao usuário do sistema, como: exercer a função de responsável pela limpeza de artigos e pela imunização $(p=0,22)$; exercer a função de responsável pela limpeza de artigos e pelos curativos $(p=1)$; exercer a função de responsável pela esterilização e curativo $(p=1)$; exercer a função de responsável pela esterilização e coleta de exames $(p=1)$; Nenhum desses resultados apresentou associação estatística significativa,
Quando considerados o p-valor $\leq$ a 0,05

Em relação aos equipamentos de proteção individual, utilizados pelo ocupacional durante a limpeza dos artigos, dos entrevistados, 14,5\% responderam Que utilizam máscaras faciais e $85,5 \%$ não usam; $38,2 \%$ utilizam óculos protetores e 61 ,7\% não usam. Com respeito ao uso das luvas, $14,7 \%$ dos ocupacionais referem utilizar um par de luvas de látex para procedimentos sobreposto a outro par de luvas emborrachadas de cano longo, 29,4\% utilizam somente luvas emborrachadas de cano longo e $55,8 \%$ utilizam luvas de látex para procedimentos. Sobre o uso dos aventais, 41, 1\% não utilizam, 32,3\% usam aventais com mangas longas em tecido sobrepostos por outro como barreira plástica e 26,4\% usam aventais em tecido com mangas curtas. Os operadores usam calçados comuns e não as botas emborrachadas. Notou-se ao associar esses dados, Que um único ocupacional realizava a limpeza dos artigos usando luvas emborrachadas, máscara facial, óculos de proteção e avental impermeável com mangas longas, porém não utilizava botas emborrachadas. Nenhum ocupacional utilizava todos os equipamentos de proteção individual recomendados (Tabela I).

Frente à complexidade do reprocessamento, era necessário identificarem-se dados sobre o tempo de atuação do operador em sua função e a capacitação recebida. Foi investigado há Quanto tempo o entrevistado trabalha na função de responsável pelo reprocessamento de artigos críticos na UBS. Notou-se Que a maioria $(73,5 \%)$ dos entrevistados estava trabalhando nesse setor no máximo há 5 anos, 11 ,7\% entre 5 e 10 anos, 5,8\% entre 10 e 15 anos, e $8,8 \%$ de 15 anos ou mais (Tabela 2).

Quando Questionado se havia recebido algum tipo de treinamento no início das atividades na função de responsáveis pelo reprocessamento de artigos críticos nas unidades básicas de saúde, verificou-se Que 67,6\% não receberam treinamento e Que apenas $32,3 \%$ haviam sido treinados.

Com relação ao treinamento, durante sua atuação como responsável pelo processo, verificou-se Que: $8,8 \%$ haviam recebido treinamento até um ano atrás; 11 ,7\% num período acima de um ano a até dois anos; $2,9 \%$ num período acima de dois anos e até três anos; $2,9 \%$ num período acima de três anos e até Quatro anos

Tabela I. Equipamentos de proteção individual adotados por responsáveis pela limpeza de artigos críticos nas unidades básicas de saúde. Campinas, 2006.

\begin{tabular}{lllc}
\hline Tipo de equipamento & Uso e características & $\mathbf{n}$ & \% \\
\hline Máscara facial & usam do tipo nariz-boca, plastificada & 5 & 14,7 \\
& não usam & 29 & 85,3 \\
Botas de borracha & não usam & 34 & 100,0 \\
Óculos de proteção & usam do tipo policarbonato, incolor, com protetores laterais & 13 & 38,2 \\
Avental de proteção & usam do tipo tecido, com mangas longas, sobreposto por barreira plástica & 11 & 32,3 \\
& usam do tipo tecido, com mangas curtas sem barreira plástica & 9 & 26,4 \\
Luva & usam do tipo látex, sobreposta por luva emborrachada & 5 & 14,7 \\
& usam do tipo látex para procedimentos & 19 & 55,8 \\
\hline
\end{tabular}


Tabela 2. Tempo do ocupacional na função de reprocessamento de artigos críticos nas unidades básicas de saúde. Campinas, 2006.

\begin{tabular}{lcc}
\hline Período de tempo & $\mathrm{n}$ & $\%$ \\
\hline 0 I---5 anos & 25 & 73,5 \\
5 I--- I0 anos & 4 & 11,7 \\
10 I--- 15 anos & 2 & 5,8 \\
$\geq 15$ anos & 3 & 8,8 \\
\hline Total & 34 & 100,0 \\
\hline
\end{tabular}

e acima de cinco anos 5,8\%. Foram encontrados $67,6 \%$ operadores Que nunca receberam Qualquer tipo de treinamento durante as atividades a serem desenvolvidas nessa função.

Para conhecer Quais foram os responsáveis pela última prática educativa realizada com os ocupacionais sobre o tema, verificouse a categoria desse profissional e a instituição Que ofereceu o treinamento. Dos 32,3\% ocupacionais Que mencionaram ter recebido treinamento Quando eram responsáveis pelo reprocessamento dos artigos nas unidades, 29,4\% receberam treinamentos oferecidos por enfermeiros das unidades e 2,9\% por treinamentos da Secretaria de Saúde do município. Os demais referiram não ter recebido nenhum treinamento sobre o tema Quando eram responsáveis pelo reprocessamento.

\section{DISCUSSÃO}

O reprocessamento adequado de artigos realizados nos estabelecimentos assistenciais de saúde demanda complexas atividades, exigindo estrutura física, recursos tecnológicos e humanos Que permitam as execuções de ações seguras fundamentadas em critérios baseados em informações científicas atualizadas ${ }^{(14)}$. Nas UBS investigadas, o reprocessamento é realizado por membros da equipe de enfermagem $(97,0 \%)$, sendo Que $88,2 \%$ são auxiliares de enfermagem e $8,8 \%$ são técnicos de enfermagem. Esse dado corrobora a Ordem de Serviços 03/0I "Processo de Trabalho Enfermagem" da Secretaria Municipal de Saúde de Campinas - SP, a Qual dispõe sobre o cumprimento das tarefas do enfermeiro, do técnico e do auxiliar de enfermagem e comunica Que:

III: Cabe ao auxiliar de Enfermagem executar sob a supervisão do Enfermeiro:

I- Considerando, para fins práticos, seu núcleo de atuação:

c- Fazer esterilização/ desinfecção/ acondicionamento de materiais"(15).

Dados semelhantes foram encontrados em um estudo realizado no Reino Unido, onde $90,0 \%$ dos responsáveis pelo uso de autoclaves em serviços primários de saúde eram "practice nurse"(16). Embora a maioria dos ocupacionais responsáveis pelo reprocessamento de artigos críticos das UBS investigadas possuísse formação específica em enfermagem, um estudo demonstrou a existência de mão de obra sem formação específica atuando em CME, dos 75 trabalhadores, $20,0 \%$ não possuíam formação específica em enfermagem, sete trabalhadores $(46,7 \%)$ atuavam nos serviços de higienização e limpeza hospitalar antes de serem inseridos no CME, Quatro $(26,6 \%)$ em serviços de portaria, três $(20,0 \%)$ em lavanderias hospitalares e um $(6,7 \%)$ em serviços domésticos ${ }^{(17)}$. Em outra investigação, conduzida por Tipple et $\mathrm{al}^{(18)}$, foi evidenciado Que em 29 Centros de Saúde da rede Municipal de Goiânia, o reprocessamento de artigos odontológicos era executado, predominantemente, por auxiliares de cirurgiões dentistas $(48,0 \%)$ e técnicos em higiene dental $(21,0 \%)$, contudo em nove unidades (3l\%), era uma atribuição de trabalhadores sem formação na área da saúde, sendo Que destes, três eram do Quadro do serviço de higienização e limpeza.

Para se trabalhar com o reprocessamento de artigos críticos, a formação profissional é importante, porém por si só, não é suficiente para garantir Que o operador realize o reprocessamento com embasamentos técnicos-científicos necessários a Qualidade. Devem ser desenvolvidos programas contínuos de treinamentos e dos trabalhadores $^{(17)}$, investimentos esses Que assegurem a capacitação profissional.

Todas as atividades envolvidas no reprocessamento de artigos críticos devem ser supervisionadas por pessoa Qualificada e competente $^{(7)}$. Desta forma, é compreensível Que a responsabilidade técnica pelo reprocessamento de artigos críticos nas unidades básicas de saúde estudadas esteja legalmente atribuída ao enfermeiro. Embora esse não realize o reprocessamento de artigos críticos, deve possuir conhecimentos básicos para o planejamento e avaliação desse processo para permitir o desenvolvimento de práticas educativas à serem aplicadas aos ocupacionais responsáveis pelo reprocessamento de artigos críticos nas unidades básicas de saúde. De acordo com a Lei $\mathrm{n}^{\circ} 7.498$, de 25 de junho de 1986 Que dispõe sobre a regulamentação do exercício da Enfermagem ${ }^{(19)}$ :

"Art. I I - O Enfermeiro exerce todas as atividades de enfermagem cabendo- Ihe:

I- privativamente:

c) planejamento, organização, coordenação, execução e avaliação dos serviços de assistência de enfermagem;

II - como integrante da equipe de saúde:

e) prevenção e controle sistemático de infecção hospitalar e de doenças transmissíveis em geral. f) prevenção e controle sistemático de danos que possam ser causados á clientel durante a assistência de enfermagem.

Art. 15 - As atividades referidas nos artigos 12 (atividades desenvolvidas por auxiliares de enfermagem) e 13 (atividades desenvolvidas por técnicos de enfermagem) desta Lei, Quando exercidas em instituições de saúde, públicas e privadas, e em programas de saúde, somente podem ser desempenhadas sob orientação e supervisão de Enfermeiro".

Conforme as diretrizes é recomendável Que o enfermeiro assuma as responsabilidades de toda atividade envolvendo o reprocessamento de artigos críticos. Portanto, se faz necessário Que essas funções sejam supervisionadas por pessoa Qualificada e competente para desenvolver atividades de educação e treinamentos aos envolvidos com o processo ${ }^{(7)}$.

Embora o reprocessamento de artigos críticos seja considerado como uma atividade de cuidado indireto, exerce influência na Qualidade da assistência direta, devendo ser visto como importante e primordial $^{(20)}$. Das unidades investigadas, $29,4 \%$ não previam um ocupacional específico escalado diariamente para assumir as atividades com exclusividade na CME, os Quais exerciam paralelamente outras funções. Assim, o reprocessamento de artigos críticos se torna uma tarefa de trabalho coletivo, ou seja, destinado ao ocupacional Que 
detiver menor número de atividades no dia. Desta maneira entendese Que QualQuer colaborador pode atuar no reprocessamento, e que o fator delimitador serão as tarefas do dia-a-dia.

Faz-se necessário pontuar, no entanto, a existência de um problema nos processos de trabalho coletivo: prática simplista de um conjunto de pessoas trabalhando num mesmo espaço, com objetivos regidos por pontos de vista, necessidades e interesses particularizados de trabalhadores, com linguagem não unificada, assim como os resultados esperados, ficando aQuém do esperado ${ }^{(21)}$. Esta situação pode colocar em risco a Qualidade do reproces-samento, a segurança do usuário, ambiental e profissional.

Essa situação também foi evidenciada em outro estudo, Quando verificado entre os técnicos e auxiliares de enfermagem da rede de serviços municipal de saúde de Natal, RN, Que as atividades desenvolvidas pelos mesmos nas unidades básicas de saúde são cumulativas. Essas atividades incluem preparo do cliente para atendimento médico/enfermagem, realização de curativo, preparo de material para esterilização, administração de medicação prescrita e vacinação ${ }^{(8)}$.

Sabe-se Que a segurança do reprocessamento de artigos críticos é uma importante medida de controle de infecção hospitalar, sendo este um grave problema de saúde pública devido as suas implicações sociais e econômicas ${ }^{(22)}$. A segurança do reprocessamento dos artigos críticos é uma importante medida de controle de infecção, pois se QualQuer etapa do processo for realizada sob condições adversas, implicará em exposição aos riscos biológicos, tanto ao cliente como para os ocupacionais envolvidos. Artigos inadequa-damente limpos ou esterilizados tornam-se fonte de contaminação, pois são amplamente utilizados em procedimentos invasivos e oportunos para a propagação de infecção cruzada ${ }^{(6)}$. É difícil considerar especificamente as falhas no processo de esterilização de artigos como fatores causais de infecções, pois sabe-se Que o processo infeccioso é multifatorial, e não se pode descartá-los se o processo não for devidamente planejado e sistematizado pelo enfermeiro ${ }^{(23)}$.

Sabe-se Que os atuais planos do governo, pretendem expandir os controles de infecção não apenas em hospitais, mas para todo o sistema de saúde, com a ampliação da abrangência das ações de prevenções e controle das infecções hospitalares para os demais serviços de saúde, por meio da Gerência de Investigação e Prevenção das Infecções e dos Eventos Adversos ${ }^{(24)}$. Porém, como falar em controle infecção, se o reprocessamento de artigos críticos não se realizar de forma sistemática?

Os métodos de reprocessamento devem prever desde a limpeza e descontaminação de forma Que o risco de transmissão de infecção para todos os pacientes seja evitado ${ }^{(25)}$. Observou-se Que atividades paralelas, junto ao reprocessamento de artigos foram assumidas pelos ocupacionais no dia da entrevista. Quando esses atuavam na realização da limpeza dos artigos, também eram responsáveis pela imunização $(8,82 \%)$ e pela realização de curativos $(26,4 \%)$.

A vivência diária com atividades realizadas nas unidades, sugere Que devido às licenças de saúde, remanejamentos e substituições de funcionários, pode ocasionar um número insuficiente de recursos humanos necessários ao atendimento direto e indireto à população usuária das unidades básicas de saúde. Outro ponto à ser discutido, refere-se à atividades intermitentes, gerando lacunas de tempo ocioso, Que pode ser otimizado, intercalando-as. Sendo assim, para suprir a demanda da assistência ao usuário, e otimizar a força de de trabalho, deve ocorrer o gerenciamento das atividades à serem desenvolvidas, prevendo as prioridades e organizando as atividades, de modo Que, ofereçam segurança e garantam a Qualidade para Que se pretende.

Sabe-se Que os artigos Que serão submetidos à limpeza, contém sujidades, podendo essas conter contaminantes com presença de material microbiológico, Que deve ser manipulado com cautela. Para se evitar o risco da exposição do trabalhador e do ambiente à esses patógenos e para se assegurar de Que os artigos após a limpeza estejam insentos de contaminação, critérios estabelecidos devem ser seguidos. Portanto, é fundamental Que pessoas Que trabalham em área de descontaminação usem equipamentos de proteção individual. Esses dispositivos ou produtos de uso individual, destinam-se à proteção contra riscos à saúde e à segurança ao trabalho ${ }^{(1)}$. Para a realização da limpeza dos artigos é indicado Que os operadores usem vários eQuipamentos de proteção individual, conjuntamente, como aventais de proteção impermeáveis, luvas, galochas de borracha, máscaras faciais, protetores oculares ${ }^{(7)}$.

Mesmo Que a possibilidade à exposição biológica do ocupacional durante a realização da limpeza seja prevenida com o uso de eQuipamentos de proteção individual e com a lavagem das mãos antes e depois da prática ${ }^{(26)}$, não é aconselhável Que o responsável pela área contaminada, realize curativos e imunização, pois são procedimentos antagônicos, exigindo cuidados rigorosos com a assepsia.

Entre os operadores responsáveis pela esterilização dos artigos, verificou-se Que também eram responsáveis tanto pela realização de curativos $(26,4 \%)$ como pela coleta de exames laboratoriais (sangue, urina, fezes) e colpocitológicos $(52,4 \%)$. Pode-se admitir Que existe possibilidades de exposição a contaminação desses artigos durante o manuseio na área de preparo e esterilização. Nesse caso, durante a participação nesses procedimentos, devem ser realizadas a correta higienização das mãos, e a utilização de aventais de sobreposição ou troca das roupas, antes de trabalhar nas atividades com o reprocessamento. Os locais onde estes artigos são processados e as pessoas Que os manuseiam também podem tornar-se fontes de infecção para hospedeiros suscetíveis.

Entende-se que a garantia do processo de esterilização deve ser respeitado em todas as etapas do mesmo, assegurando o reprocessamento dos artigos ${ }^{(8)}$.

Recomenda-se Que todos os equipamentos de proteção individual sejam utilizados conjuntamente para a descontaminação dos artigos ${ }^{(1)}$. Dos equipamentos de proteção individual adotados pelos ocupacionais durante a limpeza dos artigos contaminados, percebe-se uma baixa adesão tanto ao uso de forma isolada ou conjuntamente. Todo serviço de saúde Que contemple áreas de exposição do trabalhador a riscos biológicos deverá adotar um Programa de Prevenção de Riscos Ambientais revisado periodicamente.

Esse programa deverá conter medidas de proteção à exposição aos agentes biológicos e a providência de equipamentos de proteção individual descartáveis ou não disponibilizados em número suficiente nos postos de trabalho. Essas medidas devem ser adotadas e seguidas pelos ocupacionais ${ }^{(26)}$. O fato de ter sido identificado que os ocupacionais não fazem o uso adequado dos equipamentos de proteção individual, suscita em uma investigação, pois não se sabe se essa atitude é decorrente da não disponibilização desses recursos ou por desconhecimento do usuário. 
Sabe-se Que conceitos sobre esterilização podem não ser compreendidos por ocupacionais Que realizam atividades com o reprocessamento, demonstrando desconhecimentos aos riscos de infecção cruzada e métodos seguros de descontaminação de instrumentais ${ }^{(27)}$. A maioria dos ocupacionais das unidades básicas de saúde estudadas trabalhou em um período entre 0-5 anos $(73,5 \%)$, $32,3 \%$ receberam treinamento inicial ao assumir o reprocessamento de artigos da UBS, e 67,6\% nunca receberam nenhum tipo de treinamento, portanto é aconselhável Que a capacitação dos trabalhadores seja inserida de forma continuada, por meio de instruções escritas em linguagem acessível e compreensível sobre as rotinas realizadas no local de trabalho e medidas de prevenção de acidentes e de doenças relacionadas ao trabalho ${ }^{(11,26)}$, pois a Qualificação do operador terá notável influência nos processos estabelecidos e na prevenção e controle de infecção ${ }^{(17)}$.

No estudo de Cavalcante e Macedo ${ }^{(8)}$, a ausência de educação continuada em serviço foi a principal dificuldade citada por técnicos e auxiliares de enfermagem das unidades básicas de saúde Natal, $\mathrm{RN}$, para o desenvolvimento de suas atividades.

Os recursos humanos selecionados para atuar nas atividades de reprocessamento de artigos críticos devem ser estimulados a participar de treinamento continuado, permitindo atualizações e assegurando Que aos profissionais exerçam essas atividades com conhecimento técnico-científico necessário ${ }^{(17)}$. O treinamento e avaliação constantes do conhecimento e desempenho nos processos devem ser vistos como relevantes e prioritários ${ }^{(28)}$. Devem ser preparados adecuadamente para as funções Que assumem, pois embora não estejam prestando uma assistência direta ao usuário, executam atividades Que refletirão diretamente nessa assistência ${ }^{(29)}$.

O trabalho dos responsáveis pelo reprocessamento de artigos críticos abrange muito mais do Que receber, limpar, acondicionar, esterilizar, guardar e distribuir artigos, e manusear equipamentos de complexa tecnologia. Exige educação em serviço, monitorização de processos, aquisição e testes de produtos e materiais, envolvendo as interfaces com outros serviços.

O uso incorreto de equipeamentos de proteção individual, somado às atividades mencionadas realizadas pelos operadores concomitantemente ao reprocessamento, e o baixo nível de identificação de ocupacionais capacitados para exercer essa atividade potencializam a possibilidade de disseminação de infecção no ambiente de trabalho, do risco ocupacional e a segurança ao próprio usuário.

A atenção voltada à gestão em Qualidade lentamente vem sendo adotada pelas instituições de saúde. A preocupação com a Qualidade está deixando de ser rapidamente um diferencial e uma opção para se tornar imperativa, um pré-requisito básico para a sobrevivência e a competitividade das organizações do mundo moderno ${ }^{(3)}$. Porém, na prática, o setor público da saúde coletiva demonstra interesse pela avaliação de programas de saúde e, até o momento, discreto interesse pelas avaliações de Qualidade e tecnologias usadas para o atendimento ao usuário ${ }^{(5)}$. Não há um programa de gestão em Qualidade que atenda a demanda necessária para o reprocessamento de artigos críticos realizados nas unidades estudadas.

Princípios básicos de Qualidade em saúde recomendam Que o atendimento à clientela seja realizado com o fornecimento de bens e de serviços Que promovam a sua máxima satisfação e o mínimo, senão a ausência total de riscos e falhas Que possam comprometer a Qualidade e a segurança ${ }^{(4)}$. Portanto, falar em reprocessamento de artigos é pensar em Qualidade de serviço favorecendo as melhores implicações ao usuário. O controle de Qualidade será satisfatório, Quando os procedimentos adotados, em cada etapa, encontrarem-se de acordo com critérios préestabelecidos, originários de investigações e normas oficiais.

O conhecimento de conceitos básicos sobre o reprocessamento de artigos críticos deve estar atrelado a sua adequada prática. De Que forma a utilização do conhecimento pode ser inserido em processos históricos concretos, Que além de terem delimitado as suas condições de produção, estarão também interferindo nas suas condições de utilização? ${ }^{(5)}$.

Talvez a integração entre instituições de ensino e as UBS possa contribuir com ações para sistematizar o reprocessamento de artigos críticos nas unidades e capacitar seus responsáveis. A Educação Permanente em Saúde, é um conceito pedagógico, instituído como política de saúde pela Portaria do Ministério da Saúde no 198, de 13 de fevereiro de $2004^{(30)}$. Pretende-se efetuar relações orgânicas entre docência e atenção a saúde, agregando o aprendizado, reflexão crítica sobre o trabalho e resolutividade da clínica e da promoção da saúde coletiva e em saúde. É uma estratégia do Sistema único de Saúde para a formação e desenvolvimento de trabalhadores, para promover a aprendizagem no trabalho, Que o aprender e o ensinar se incorporam ao Quotidiano das organizações e ao trabalho. Procura transformar as práticas profissionais e institucionais, melhorando a capacidade de atenção proporcionada, promovendo o comprometimento com o processo de trabalho e a comunidade, incrementando as relações entre as equipes de trabalho ${ }^{(30)}$.

Uma proposta efetiva de um pólo de educação permanente em saúde para a condução de alternativa para a melhora da Qualidade envolvendo o reprocessamento de artigos críticos nas unidades básicas de saúde, poderia contribuir com o desenvolvimento de capacitação de ocupacionais Que trabalham com o reprocessamento, produzindo impacto positivo sobre a saúde individual e coletiva, envolvendo atividades discentes de cursos de graduação de enfermagem com todas as UBS municipais. Para tal, foi idealizado uma proposta de equipeamentos de proteção individual para ser apresentada aos responsáveis pelos distritos de saúde com o objetivo de capacitar os responsáveis pelo reprocessamento de artigos críticos nas UBS do município do estudo.

\section{CONCLUSÃO}

O reprocessamento de artigos críticos é rotineiramente utilizado nas unidades estudadas em procedimentos odontológicos, curativos, suturas, pequenos procedimentos cirúrgicos e ginecológicos, realizado predominantemente por auxiliares de enfermagem.

Os operadores responsáveis pelo reprocessamento de artigos críticos exerciam funções concomitantes como imunizações, curativos e coleta de exames. O uso incorreto de equipamentos de proteção individual, somado às atividades mencionadas realizadas pelos operadores, concomitantemente, ao reprocessamento, e o baixo nível de identificação de ocupacionais capacitados para exercer essa atividade, potencializam a possibilidade de disseminação de infecção no ambiente de trabalho, do risco ocupacional e a segurança ao próprio usuário. O reprocessamento de artigos críticos na maioria das UBS estudadas está sendo realizado por ocupacionais não capacitados para atuarem embasados por informações científicas. 
Sugere-se Que uma adequação da política de Educação Permanente poderá ser implementada para alcançar melhorias na Qualidade do reprocessamento dos artigos críticos desenvolvidos nessas unidades básicas de saúde.

Os achados identificados nesta pesQuisa auxiliarão no planejamento das propostas de intervenções nas práticas educativas contínuas sobre o reprocessamento de artigos críticos, para Qualificar os ocupacionais das unidades responsáveis pelo processo. Essa ação, influenciará na promoção da saúde da população assistida nos serviços primários, assim como na Qualidade da gestão em saúde.

\section{REFERÊNCIAS}

1. Ministério da Saúde (BR). Agência Nacional de Vigilância Sanitária - Resolução - RE No 2606, de II de agosto de 2006. Dispõe sobre as diretrizes para elaboração, validação e implantação de protocolos de reprocessamentos de produtos médicos e dá outras providências. Diário Oficial União 2006 ago 14.

2. Angerami ELS. O mister da investigação do enfermeiro. Rev Latino-am Enfermagem I993; I (1): I I-22.

3. Nogueira LCL. Gerenciando pela Qualidade total na saúde. $2^{\mathrm{a}}$ ed. Belo Horizonte: Desenvolvimento Gerencial; 1999.

4. Azevedo AC. O futuro dos hospitais e a gestão da Qualidade. Rev Paul Hosp 1992; 40(5/12): 53-9.

5. Novaes HMD. Avaliação de programas, serviços e tecnologias em saúde. Rev Saúde Pública 2000; 34(5): 547-59.

6. Drumond DC, Skildmore AG. Sterilization and disinfection in the physican's office. Can Med Assoc I 1991; 1 45(8): 937-43.

7. Association for the Advancement of Medical Instrumentation, American National Standard Institute. Steam sterilization and sterility assurance in health care facilities. Washington: ANSI; 2002.

8. Cavalcante CAA, Macedo MLAF. Estudo do perfil dos auxiliares e técnicos de enfermagem: rede de serviços da secretaria municipal de saúde Natal/RN [dissertação]. Natal: Universidade Federal do Rio Grande do Norte; 2000,

9. Antunes AV, Costa, MN. Dimensionamento de pessoal de enfermagem em um hospital universitário. Rev Latino-am Enfermagem 2003; 11 (6): 832-9

10. Secretaria Municipal de Saúde de Campinas. [citado em 30 mai 2005]. Disponível em: http://www.campinas.sp.gov.br.

I I. Rutala WA, Weber DJ. Health Infection Control Parctices Advisory Committee. Draft Guideline for Disisnfection and Sterilization in Helthcare Facilities. Center for Disease Control Atlanta: CDC; 2002. [cited 2008 mar 8]. Available from: http://www.cdc.gov

12. Ministério da Saúde (BR). Resolução da Diretoria Colegiada da Agência Nacional de Vigilância Sanitária - RDC no 50, de 21 de fevereiro de 2002. Dispõe sobre o Regulamento Técnico para planejamento, programação, elaboração e avaliação de projetos físicos de estabelecimentos assistenciais de saúde Brasil. Diário Oficial União 2002 mar 20.

13. Ministério da Saúde (BR). Resolução da Diretoria Colegiada da Agência Nacional de Vigilância Sanitária - RDC no 307, de 14 de novembro de 2002. Altera a RDC no 50 de 2 I de fevereiro de 2002 e dispõe sobre o regulamento técnico para planejamento, programação, elaboração e avaliação de projetos físicos de estabelecimentos assistenciais de saúde. Diário Oficial União 2002 nov 18.

14. Secretaria de Estado da Saúde de Estado de São Paulo. Divisão de Infecção Hospitalar. Centro de Vigilância Epidemiológica. Manual de Avaliação da Qualidade de Práticas de Controle de Infecção Hospitalar. Projeto de parceria multiprofissional e multi- institucional de política pública de saúde na área de controle de infecção hospitalar. São Paulo: Imprensa Oficial; 2006.

15. Secretaria Municipal de Saúde de Campinas. Processo de trabalho - Enfermagem. Ordem de serviço no3 /200l do Gabinete do Secretário de Saúde. Comunicado aos coordenadores de serviços de saúde e equipe de enfermagem. [citado 3 I mar 2008]. Disponível em: http://www.campinas.sp. gov.br./saude/programas/protocolos/processo_trabalho_ enfermagem.

16. Coulter WA, Chew-Grahan CA, Cheung SW, Burke FIT. Autoclave performance and operator knowledge of autoclave use in primary care: a survey of UK practices. I Hosp Infec 200 I; 48(3): 180-5.

17. Tipple AFV, Souza TR, Bezerra ALQ, Munari DB. O trabalhador sem formação em enfermagem atuando em centro de material e esterilização: desafio para o enfermeiro. Rev Esc Enferm USP 2005; 39(2): 173-80.

18. Tipple AFV, Souza ACS, Nakatani AYK, Carvalho MVC, FariaRS, Paiva EMM. O processamento de artigos odontológicos em centros de saúde de Goiânia. Rev Robrac 2004; 1 4(37): 4- 17.

19. Brasil. Lei n. 7.498 de 25 de junho de 1986. Dispõe sobre a regulamentação do exercício da enfermagem e dá outras providências. Diário Oficial União 1986 jun 26; 9273-5.

20. Bartolomei SR, Lacerda RA. O enfermeiro da Central de Material e Esterilização e a percepção do seu papel social. Rev Gaúcha Enferm 2006; 27(2): 258-65.

21. Rossi FR. Tecnologias leves nos processos gerenciais do enfermeiro: contribuição para o cuidado humanizado [dissertação]. Porto Alegre: Escola de Enfermagem, Universidade Federal do Rio Grande do Sul; 2003.

22. Brito MFPB, Galvão CM, Francolin L, Rotta CSG. Validação do processo de esterilização de artigos médico-hospitalares segundo diferentes embalagens. Rev Bras Enferm 2002; 55(4): 41 4-9.

23. Ministério da Saúde (BR). Coordenação de Controle de Infecção Hospitalar. Processamento de Artigos e Superfícies em Estabelecimentos de Saúde. $2^{\text {a }}$ ed. Brasília: Ministério da Saúde; 1994.

24. Ministério da Saúde (BR). Agência Nacional de Vigilância Sanitária. Anvisa intensifica controle de infecção em serviços de saúde.Informes técnicos institucionais. Rev Saúde Pública 2004; 38(3): 1-6.

25. Alfa M. Medical-device reproccessing. Infect Control Hosp Epidemiol 2000; 21 : 496-98.

26. Ministério do Trabalho (BR). Portaria MTE n. 485 de 11 de novembro de 2005. Norma Regulamentadora - NR no 32. Dispõe sobre o estabelecimento das diretrizes básicas para a implementação de medidas de proteção à segurança e à saúde dos trabalhadores dos serviços de saúde, bem como daqueles Que exercem atividades de promoção e assistência à saúde em 
geral. Diário Oficial União 2005 nov 16.

27. McNally O, Thompson IM, Mcllvenny G, Smyth ETM, McBride $\mathrm{N}$, MacAuley D. Sterilization and disinfection in general practice within university health services. J Hosp Infec 200 I ; 49: 21 0-4.

28. Bergo MCNC. Avaliação do desempenho da limpeza e desinfecção das máQuinas lavadoras desinfectadoras automáticas em programas com diferentes tempo e temperatura. Rev Latinoam Enfermagem 2006; 14(5).
29. Souza MCB, Ceribelli MIPF. Enfermagem no centro de material esterilizado a prática da educação continuada. Rev Latino-am Enfermagem 2004; 12(5): 767-74.

30. Ministério da Saúde (BR). Portaria n. 198/ GM/ MS de 13 de fevereiro de 2004. Institui a Política Nacional de Educação Permanente em Saúde como Estratégia do Sistema Único de Saúde para a formação e o desenvolvimento de trabalhadores para o setor e dá outras providências. Diário Oficial União 2004 fev 16. 